\section{Central (garland) aortopulmonary shunt}

A 24-year-old woman, with unoperated tetralogy of Fallot, presented with refractory cyanosis and was listed for emergency palliative shunt surgery. Preoperative cardiac catheterisation or CT angiography could not be performed. The size of the pulmonary artery (PA) appeared borderline on echocardiographic assessment. A central shunt, connecting the ascending aorta to the main PA, was created using a $6 \mathrm{~mm}$ polytetrafluoroethylene (PTFE) prosthesis. The central shunt was chosen because it was an emergency procedure, the sizes of the left and right PAs (LPA, RPA) were borderline, and there were multiple collaterals from the subclavian artery. The patient's condition stabilised and she was discharged with a plan for corrective surgery on follow-up. At 6 months post-surgery, she was asymptomatic with an arterial oxygen saturation of $80 \%$ at room air. Cardiac auscultation revealed a continuous murmur suggestive of a patent shunt. Preoperative catheterisation demonstrated a patent garland shaped central shunt (figure 1A, B and online supplementary video 1), with the LPA being smaller than the RPA.

The advantages of a central shunt include simultaneous growth of both the RPA and LPA, ${ }^{1}$ minimal iatrogenic branch PA distortion, reduced incidence of PA stenosis, lower occlusion rates, and ease of closure during corrective surgery. ${ }^{2}$ Disadvantages include risk of over-shunting with development of pulmonary arterial hypertension (PAH) and injury to the shunt during sternotomy. Increasing the length of the shunt (as in our case, figure 1) prevents over-shunting/development of $\mathrm{PAH}$ by increasing the resistance to blood flow.

\section{Shrenik R Doshi, Himanshu Gupta, S Ramakrishnan}

Department of Cardiology, All India institute of Medical Sciences, New Delhi, India

Correspondence to Dr S Ramakrishnan, Department of Cardiology, All India institute of Medical Sciences, New Delhi 110029, India; ramaaiims@gmail.com

- Additional material is available. To view please visit the journal online (http://dx. doi.org/10.1136/heartasia-2014-010597).

Contributors SRD and HG handled the case from the beginning and also wrote the manuscript under the guidance of SR.

Competing interests None.

Provenance and peer review Not commissioned; externally peer reviewed.

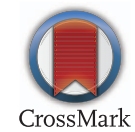

To cite Doshi Shrenik R, Gupta H, Ramakrishnan S. Heart Asia 2015;0:8. doi:10.1136/heartasia-2014-010597

Heart Asia 2015;0:8. doi:10.1136/heartasia-2014-010597

\section{REFERENCES}

1 Yuan SM, Jing H. Corrigendum to "Palliative procedures for congenital heart defects". Arch Cardiovasc Dis 2009;102:549-57.

2 Longaker MT, Merrick S, Crombleholme TM, et al. Systemic-to-pulmonary artery shunt using the internal mammary artery. Ann Thorac Surg 1989;47:464-5.

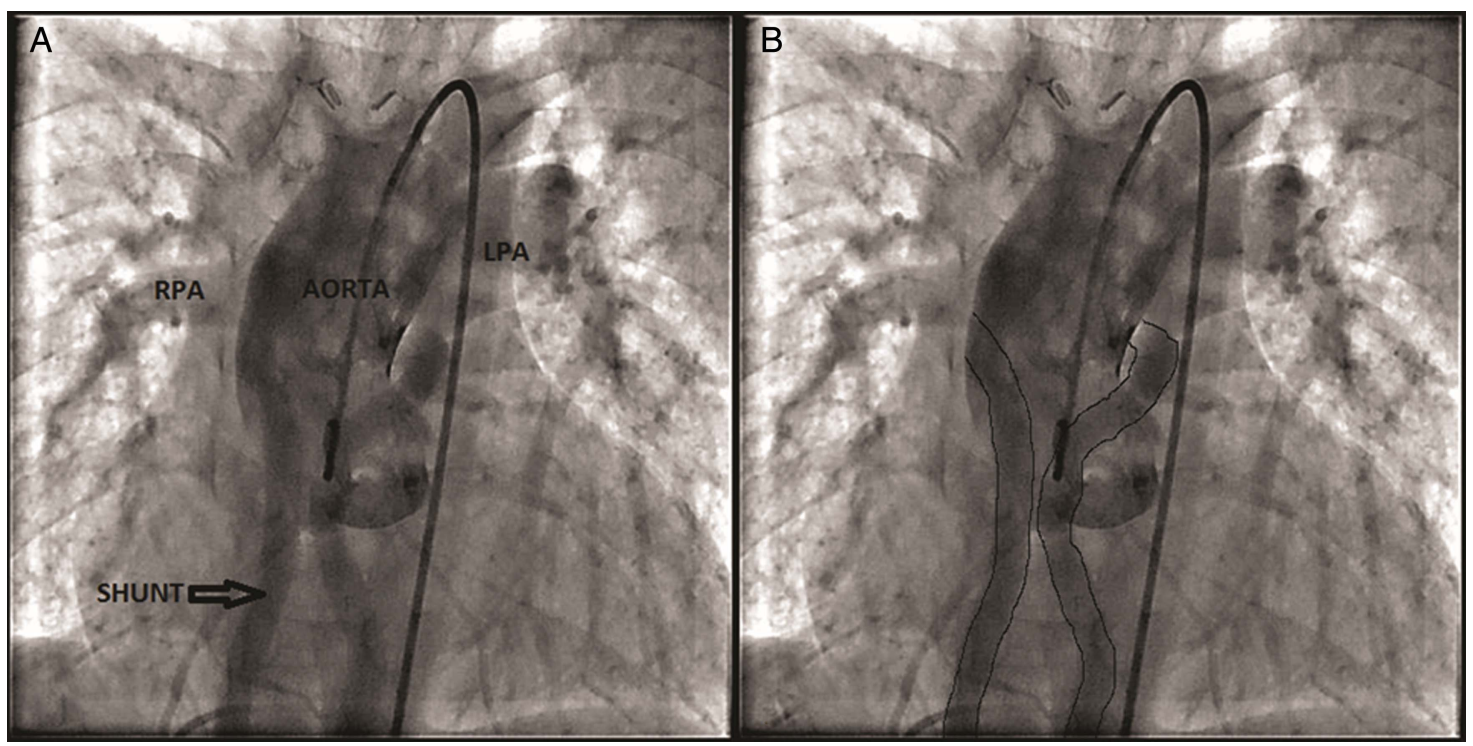

Figure 1 (A) Aortic root angiogram demonstrating a patent central shunt connecting the ascending aorta to the main pulmonary artery and simultaneous filling of both pulmonary arteries. (B) The garland shaped central shunt is shown. LPA, left pulmonary artery; RPA, right pulmonary artery. 